\title{
A Prodrug-doped Cellular Trojan Horse for the Potential Treatment of
}

\section{Prostate Cancer}

Oren Levy ${ }^{1,2,3,4^{*}}$, W. Nathaniel Brennen ${ }^{5 *}$, Edward Han ${ }^{1,2,3,4}$, David Marc Rosen ${ }^{5}$, Juliet Musabeyezu ${ }^{1,2,3,4}$, Helia Safaee ${ }^{1,2,3,4}$, Sudhir Ranganath ${ }^{1,2,3,4}$, Jessica Ngai ${ }^{1,2,3,4}$, Martina Heinelt ${ }^{1,2,3,4}$, Yuka Milton ${ }^{1,2,3,4}$, Hao Wang ${ }^{7}$, Sachin H. Bhagchandani ${ }^{1,2,3,4}$, Nitin Joshi ${ }^{1,2,3,4}$, Neil Bhowmick ${ }^{6}$, Samuel R. Denmeade ${ }^{5 *}$, John T. Isaac5 ${ }^{5 *}$ and Jeffrey M. Karp ${ }^{1,2,3,4^{*} \S}$

${ }^{1}$ Division of Biomedical Engineering, Department of Medicine, Center for Regenerative Therapeutics, Brigham and Women's Hospital, ${ }^{2}$ Harvard Medical School, ${ }^{3}$ Harvard Stem Cell Institute, ${ }^{4}$ Harvard - MIT Division of Health Sciences and Technology, ${ }^{5}$ The Sidney Kimmel Comprehensive Cancer Center at Johns Hopkins, ${ }^{6}$ The Samuel Oschin Comprehensive Cancer Institute at the Cedars-Sinai Medical Center, ${ }^{7}$ Department of Oncology, Division of Biostatistics at the Sidney Kimmel Comprehensive Cancer Center.

* Authors have contributed equally to this study.

${ }^{\S}$ Corresponding authors: Samuel Denmeade (denmesa@jhmi.edu), John Isaacs (isaacjo@jhmi.edu) and Jeffrey Karp (jeffkarp.bwh@gmail.com).

\section{ABSTRACT}

Despite considerable advances in prostate cancer research, there is a major need for a systemic delivery platform that efficiently targets anti-cancer drugs to sites of disseminated prostate cancer while minimizing host toxicity. In this proof-of-principle study, human mesenchymal stem cells (MSCs) were loaded with poly(lactic-co-glycolic acid) (PLGA) microparticles (MPs) that encapsulate the macromolecule G114, a thapsigargin-based prostate specific antigen (PSA)-activated prodrug . G114- 
particles ( 950 $\mathrm{nm}$ in size) were internalized by MSCs, followed by the release of G114 as an intact prodrug from loaded cells. Moreover, G114 released from G114 MP-loaded MSCs selectively induced death of the PSA-secreting PCa cell line, LNCaP. Finally, G114 MP-loaded MSCs inhibited tumor growth when used in proof-of-concept co-inoculation studies with CWR22 PCa xenografts, suggesting that cell-based delivery of G114 did not compromise the potency of this pro-drug in-vitro or in-vivo. This study demonstrates a potentially promising approach to assemble a cell-based drug delivery platform, which inhibits cancer growth in-vivo without the need of genetic engineering. We envision that upon achieving efficient homing of systemically infused MSCs to cancer sites, this MSC-based platform may be developed into an effective, systemic 'Trojan Horse' therapy for targeted delivery of therapeutic agents to sites of metastatic PCa.

Prostate cancer ( $\mathrm{PCa}$ ) is the second most common cancer and the second leading cause of cancerrelated deaths in American men. Currently affecting over 2.5 million Americans, 1 in 7 men in the U.S. will be diagnosed with PCa in their lifetime. PCa lethality is fueled by the development of disseminated metastases, which are commonly found in the bone, lymph nodes, liver and lungs ${ }^{1-3}$. Despite the impressive progress in PCa research and the availability of therapies such as surgery, radiation, hormonal therapy, immunotherapy and chemotherapy, there remains a significant need for more effective therapies for castration-resistant metastatic $\mathrm{PCa}^{1,3-7}$. Specifically, there is a major need to efficiently target systemically administered anti-cancer drugs to sites of PCa metastasis while minimizing host toxicity. Systemic administration of therapeutic agents typically encounters multiple challenges including severe adverse effects due to systemic toxicity, uncontrolled drug levels, premature enzymatic/chemical inactivation and rapid drug clearance requiring repeated dosing ${ }^{8}$. While drug encapsulation in nano/micro delivery systems may reduce host toxicity and protect the drug from early degradation, effective targeting of tumors remains elusive ${ }^{9}$. Moreover, systemically infused 
micro/nanoparticles typically remain close to blood vessels and cannot efficiently distribute the drug throughout the tumor ${ }^{10-13}$.

A potential approach to overcome such challenges is to use a cell-based platform for targeted delivery of therapeutics to sites of metastatic PCa. Known to display tropism towards cancer sites ${ }^{14-16}$, mesenchymal stem cells (MSCs) are potential candidates for delivery of therapeutic agents to sites of PCa. One advantage of using particle-loaded cells is that they might migrate away from the vasculature and deeper into the tumor to effectively distribute their toxic payload throughout the tumor. Furthermore, allogeneic MSCs can be harvested from the bone marrow of healthy donors and expanded ex-vivo using well-established, FDA-approved protocols ${ }^{17}$. Displaying immune evasiveness, these allogeneic MSCs do not need to be host matched, providing yet another advantage towards their clinical translation $^{18}$. Indeed, MSCs are being explored in over 500 clinical trials worldwide. Clinical studies have demonstrated that hundreds of millions of allogeneic MSCs can be safely administered intravenously (IV) without significant side effects ${ }^{18}$.

To further reduce host toxicity and provide yet another layer of specificity to our delivery system, we chose to use the macromolecule G114, a thapsigargin-based Prostate Specific Antigen (PSA)-activated prodrug previously developed by our group and validated using preclinical in vitro and in vivo models of $\mathrm{PCa}^{19-22}$. PSA is a serine protease that is only secreted by prostate luminal epithelial cells ${ }^{23-26}$. Although PSA is detected in the blood of PCa patients, it is enzymatically inactive due to binding with ubiquitous serum protease inhibitors such as alpha-1-antichymotrypsin ( $\alpha 1-\mathrm{AC})$ and alpha-2-macroglobulin $(\alpha 2 \mathrm{M})^{24}$. Importantly, the enzymatically active form of PSA is only present in the extracellular fluid (ECF) within the prostate and sites of PCa including metastases ${ }^{24}$. We have previously engineered G114, a cellimpermeable PSA-activated prodrug (Fig. 1a) comprised of the potent cytotoxic molecule leucine-12aminododecanoyl thapsigargin (Leu-12ADT), an amino acid-thapsigargin analog, conjugated to a unique, PSA-cleavable, five amino acid peptide substrate (i.e. HSSKLQ) ${ }^{19-21,27}$. Unproteolyzed G114 is inactive and 
cannot penetrate cells until it reaches PCa sites, where it is cleaved by PSA to liberate the active toxin, Leu-12ADT. The released lipophilic toxin rapidly enters adjacent cells and induces apoptosis in a proliferation-independent manner via inhibiton of the sarcoplasmic/endoplasmic calcium ATPase (SERCA) pump; an essential pathway for maintaining calcium homeostatsis in all cells ${ }^{28-31}$. Consequently, once liberated in the ECF, the active toxin effectively kills any adjacent cell independent of PSA expression resulting in a 'bystander effect' targeting the entire microenvironment to overcome tumor heterogeneity ${ }^{22,28,32}$. Therefore, G114 represents a PSA-targeted agent with previously validated selective anti-tumor efficacy in preclinical models of $\mathrm{PCa}^{20}$. Unfortunately, G114, like other peptidebased prodrugs, suffers from unfavorable pharmacokinetics with a plasma half-life of only a few hours due to renal clearance. Thus, G114 is a suitable pro-drug for initial evaluation of our particle-in-a-cell delivery platform.

In this proof-of-concept study, we aimed to engineer MSCs as a G114 delivery platform for PCa therapy independent of genetic manipulation (Scheme 1). First, we sought to encapsulate G114 in poly(lactic-coglycolic acid) microparticles (PLGA MPs). PLGA is already present in FDA-approved products; it is a biodegradable, biocompatible polymer that enables tunable drug release $\mathrm{e}^{33-35}$ and we have previously used PLGA MPs to encapsulate small molecules to control cell phenotype ${ }^{36-38}$. Following an intricate iteration of a double emulsion protocol ${ }^{39,40}$, we succeeded in encapsulating G114, a peptide-containing prodrug (M.W. >1600g/mole), in PLGA particles ( 950nm in diameter), achieving high drug loading (>13\%) and encapsulation efficiency (>88\%). G114 MPs were then successfully internalized by MSCs without compromising their viability. G114 was released as a functional, intact prodrug in significant levels from G114-MP-loaded MSCs for up to 7 days and selectively induced cell death of PSA-secreting PCa cells in-vitro. Finally, co-inoculation in-vivo studies demonstrated the therapeutic efficacy of G114MP-loaded MSCs, suggesting that cell-based delivery of G114 did not compromise the potency of this pro-drug in-vitro or in-vivo. Overall, this study highlights the potential of G114-MP-loaded MSCs as cell- 
based delivery vehicles for PCa therapy. Furthermore, achieving efficient targeting of systemically infused MSCs to sites of PCa metastasis in future studies will facilitate the development of such drugloaded cells into a potent systemic therapy for metastatic PCa.

\section{RESULTS AND DISCUSSION}

\section{Encapsulation of G114, a PSA-cleavable macromolecule pro-drug, in PLGA microparticles}

G114 is composed of a thapsigargin-based toxin and a previously optimized PSA-cleavable peptide sequence (i.e. HSSKLQ) ${ }^{20,27}$, which confers its specificity (Fig. 1a). Hence, we modified a double emulsion protoco $^{38-40}$ to encapsulate G114 in PLGA MPs. Drug amounts, polymer molecular weight, MP size, solubility parameters and homogenization velocity were rigorously iterated to accomplish high drug loading and encapsulation efficiency of the intact, peptide-containing prodrug (M.W. $=1684 \mathrm{~g} / \mathrm{mole})$ in PLGA MPs. To determine drug loading in the G114-MPs, MPs were lysed overnight using NaOH-SDS, and G114 levels in MP lysates were measured using a microBCA assay against a standard curve of free G114. G114 was successfully encapsulated in spherical PLGA MPs (Fig. 1b), with drug loading (mass of drug over total MP mass) of approximately $13 \%$ and encapsulation efficiency of over $88 \%$ (fraction of drug mass encapsulated in MPs of the initial mass of drug used in MP fabrication), which are indicative of an efficient encapsulation process (Fig. 1C). The average size of a G114-MP was 950nm (Fig. 1C), within the range which was previously shown by our group to be suitable for successful internalization of PLGA MPs by MSCs followed by sustained release of drugs from MP-loaded cells ${ }^{36-38}$. Importantly, LCMS analysis demonstrated that drug-loaded MPs (without cellular internalization) displayed sustained release of significant amounts of the intact prodrug over time (Fig. 1d), with $2.5 \mathrm{mg}$ of G114-MPs releasing more than $70 \mu \mathrm{g}$ of drug within 10 days, which is equivalent to $20.56 \%$ of the total encapsulated drug. 


\section{Intact G114 pro-drug is released from G114-MP-loaded cells}

Next, we sought to assess the impact of the G114-loaded PLGA MPs on MSCs, which are the intended cellular carriers for the MPs. Following incubation of the G114-MPs with MSCs at different concentrations (0.025-0.5 mg/mL for $15 \mathrm{~h})$, we assessed MSC viability via XTT. As shown in Fig. 2a, G114MPs did not induce significant toxicity in MSCs at concentrations up to $0.5 \mathrm{mg} / \mathrm{mL}$. Based on this data and our previous work ${ }^{38}, 0.1 \mathrm{mg} / \mathrm{mL}$ was chosen as the working concentration for subsequent experiments. Of note, MSC immunophenotyping analysis to assess the expression levels of surface markers in response to incubation with blank MPs and G114-MPs demonstrated that MSC expression of key surface markers was not altered in response to MP incubation (Supp. Fig. 1). We then tested whether G114-MPs would be internalized by MSCs. For this, we fabricated dye-encapsulating PLGA MPs with similar properties ( $\sim 1 \mu \mathrm{m}$ in diameter) and used flow cytometry and confocal microscopy to explore their interaction with MSCs. Flow cytometry demonstrated association of the MPs with MSCs (Fig. 2b) and confocal microscopy confirmed that the MPs are not only associated with the cell surface, but are indeed fully internalized by MSCs (Fig. 2c). To assess drug release from G114-MP-loaded MSCs, G114doped cells were incubated with $10 \%$ FBS-supplemented MEM- $\alpha$ media, which was collected and replaced with fresh media at indicated time points, followed by LCMS analysis for measurement of G114 and the liberated active toxin in the media. LCMS analysis revealed that G114 is released from G114 MPloaded MSCs at significant levels (Fig. 2d), with a cumulative amount of over $5 \mu \mathrm{g}$ G114 released from $5 \times 10^{4}$ MP-loaded MSCs in 7 days, indicating the release of $116 \mathrm{pg}$ of G114 from each cell. Importantly,

over $90 \%$ of the released drug remained in the inactive PSA-cleavable prodrug form (G114), demonstrating that loading our delivery platform (MSCs) with G114 MPs enables release of the intact prodrug from the cells. 


\section{_G114 released by G114 MP-loaded MSCs kills PSA-secreting PCa cells in-vitro}

Next, we aimed to assess the impact of G114 released from MP-loaded MSCs on PCa cells. For this analysis, we used the human PCa cell line, LNCaP. These cells were isolated from a lymph node metastasis and are known to secrete enzymatically-active PSA (Fig. 3a) ${ }^{20,24,41}$. As a negative control, we used MDA-MB-231, a non-PSA-expressing breast cancer cell line (Fig. 3a) ${ }^{42}$. First, we collected supernatant from MP-loaded MSCs for $72 \mathrm{~h}$ and then applied on LNCaP cells to assess the impact of this supernatant on PCa cell viability. As shown in Fig. 3b, supernatant from MP-loaded MSCs, which was shown to contain significant amounts of G114 (Fig. 2d), was highly effective in killing the PSA-secreting LNCaP cells, inducing death in $>90 \%$ of target cells within $72 \mathrm{~h}$. To further confirm this effect, we used a transwell co-culture between MP-loaded MSCs and LNCaP cells (or MDA-MB-231 cells) to simulate the direct close proximity between cancer cells and MP-loaded MSCs that would be observed in-vivo. As shown in Fig. 3c, G114 MP-loaded MSCs induced death in 70\% of the PSA-secreting LNCaP cells within $72 \mathrm{~h}$, similar to the efficacy of free G114 $(0.5 \mu \mathrm{M})$ applied directly on the cells. Importantly, this assay also confirms that drug encapsulation into MPs and cellular internalization of MPs are required for this cellular platform to exert its toxic impact. This is demonstrated by the lack of toxicity induced by the conditioned supernatant from cells pre-treated with free G114, implying the free drug is not internalized and does not associate with the cell surface. Additionally, both assays demonstrated that MDA-MB-231 cells were less susceptible to G114-induced toxicity than PSA-secreting LNCaP cells ( 2-fold higher MDAMB-231 cell viability vs. LNCaP in both assays), confirming selectivity of the platform (Fig. 3b-c). This data strongly suggests that G114 released from MP-loaded MSCs is highly effective in selectively killing PSA-secreting PCa cells, demonstrating the promise of our cell-based therapeutic platform for potential use in PCa therapy. 


\section{G114 MP-loaded MSCs inhibit tumor growth of PCa xenografts in co-inoculation in-vivo studies}

As shown in Fig. 2, release kinetics from G114 MP-loaded cells indicates that each MP-loaded MSC releases approximately $116 \mathrm{pg}$ G114 within 7 days. Thus, the amount of drug released in a tumor can be estimated by knowing the number of G114-loaded MSCs that reach the tumor site. Accordingly, we have predicted the intra-tumoral concentration of G114 as a function of the number of MSCs in a tumor comprising $1 \times 10^{6} \mathrm{PCa}$ cells (in our subsequent co-inoculation experiments $1 \times 10^{6} \mathrm{PCa}$ cells were suspended in $200 \mu \mathrm{L}$ of matrigel) (Fig. 4a). We considered a dose range of $1 \times 10^{3}-1 \times 10^{5} \mathrm{G} 114 \mathrm{MP}$-loadedMSCs. This range was chosen to include the intra-tumoral concentration of G114 (i.e. 640nM) produced by the maximum tolerated intravenous dose (MTD) of G114 (i.e. $7 \mathrm{mg} / \mathrm{kg}$ ) ${ }^{20}$. As shown in Fig. 4 a, the bioequivalent dose (i.e. $640 \mathrm{nM}$ ) is predicted at a dose of $2 \times 10^{3}$ G114 MP-loaded MSCs per $1 \times 10^{6}$ PCa cells. This means that $2 \times 10^{3} \mathrm{G} 114-\mathrm{MP}$-loaded MSCs that reach a $200 \mu \mathrm{L}$ tumor (and are distributed across the tumor) containing $1 \times 10^{6} \mathrm{PCa}$ cells, would produce an intra-tumoral drug concentration equivalent to that achievable at the MTD when pure drug is delivered systemically. At $1 \times 10^{4}$ to $1 \times 10^{5} \mathrm{G} 114 \mathrm{MP}$-loaded MSCs, the engineered MSCs are predicted to deliver 5- to 50-times the intra-tumoral G114 concentration achieved at the systemic MTD (Fig. 4a).

To test these predictions and assess the impact of our cell-based platform on PCa xenograft growth, blank or G114 MP-loaded MSCs were co-inoculated subcutaneously with CWR22 cells into nude athymic mice at doses ranging from $1 \times 10^{3}$ to $1 \times 10^{5}$ MSCs per $1 \times 10^{6} \mathrm{PCa}$ cells in $200 \mu \mathrm{L}$ matrigel (homogenous distribution of MSCs across the inoculate can be assumed since MSCs are mixed with CWR22 cells prior to co-inoculation). CWR22 is a serially-passaged patient-derived xenograft that was selected for evaluation of in vivo efficacy because it is an independent model expressing a high concentration of enzymatically active PSA [ 2.5x more PSA in vivo than LNCaP $(477.5+/-76.5$ vs. $189.33+/-55.26$ $\mathrm{ng} / \mathrm{mL} / \mathrm{g}$ tumor, respectively)] ${ }^{43}$. As shown in Fig. $\mathbf{4 b}$, a dose-dependent inhibition of tumor growth was 
observed with near complete sterilization of the inoculum at the highest dose (i.e. $1 \times 10^{5} \mathrm{MSCs}$ per $1 \times 10^{6}$ PCa cells). At this high dose, median time to progression (TTP) was increased $>2.1$-fold relative to untreated controls and >1.4-fold relative to a comparable dose of blank MP-loaded MSCs (Fig. 4c-d). Moreover, co-inoculation with G114-loaded MSCs (loaded with a total amount of $11.6 \mu \mathrm{g}$ G114 at the maximal dose of $1 \times 10^{5} \mathrm{MSCs}$ ) did not induce systemic toxicity as indicated by an insignificant effect on body weight $[<5 \%$ change, (Fig. 4e)]. Confirming our theoretical prediction (Fig. 4a), these data demonstrate that even at a co-inoculation dose of $1 \times 10^{4}$ G114 MP-loaded MSCs to $1 \times 10^{6}$ PCa cells, our cell-based platform displays an anti-tumor effect in PCa xenografts in-vivo.

\section{Discussion}

Despite rapid progress in PCa therapy, there is still a major need to develop systemic treatments that can effectively target sites of metastatic PCa, which is known to preferentially metastasize to the bone ${ }^{1}$. Standard chemotherapies, while effectively killing cancer cells, also result in adverse side effects ${ }^{44,45}$. Encapsulation of cytotoxic agents in micro/nanoparticles has emerged over the last two decades as a promising approach to overcome some of the challenges in systemic delivery of such therapeutics ${ }^{9,46}$. Indeed, micro/nanoparticle delivery systems can protect drugs from the harsh in-vivo environment postinfusion, improve drug delivery and were also shown in some cases to augment therapeutic efficacy and reduce systemic toxicity ${ }^{9,47,48}$. Nevertheless, targeting particles to cancer sites, and especially the bone marrow, remains challenging. While nanoparticle targeting to cancer sites mostly relies on the enhanced permeability and retention (EPR) effect ${ }^{49}$, only nanoparticles smaller than $400-500 \mathrm{~nm}$ are subject to EPR, while bigger MPs cannot passively target tumors with high efficiency ${ }^{50}$. Unfortunately, nanoparticles cannot be loaded with high amounts of drug relative to the larger MPs. Furthermore, given the high surface area to volume ratio, these nanoparticles are characterized by a significant burst release of the drug and rapid clearance from the body ${ }^{51}$. Hence, the use of cellular carriers of microparticles represents a promising strategy for targeted delivery of anti-cancer drugs to cancer sites ${ }^{52-55}$. MSCs in particular 
represent a promising vector for this approach because they are known to be well tolerated by patients ${ }^{18}$ and to display cancer tropism ${ }^{14-16}$.

In this study, we report the assembly of MP-loaded MSCs as a cellular therapeutic platform to combat PCa. We have previously demonstrated loading of multiple cell types with PLGA MPs that encapsulate different agents as a means of controlling cell phenotype ${ }^{36,37,56}$. Specifically, we have shown that MSCs can be loaded with dexamethasone (Dex)-loaded PLGA MPs, eventually trigerring release of Dex to affect the adjacent microenvironment ${ }^{36}$. We have also shown that Budesonide-loaded PLGA MPs enhance MSC immunomodulatory impact and that iron oxide nanoparticle-loaded PLGA MPs can be used to track $\mathrm{MSCs}^{37,57}$. Unlike the small molecules we previously encapsulated, in this study we developed an approach to successfully encapsulate a peptide-conjugated prodrug (M.W. $=1684 \mathrm{~g} / \mathrm{mole}$ ) in PLGA MPs that were then loaded into MSCs. Thereby, expanding the range of molecules that can be incorporated and delivered via this cell-based platform. MP internalization was followed by cellular release of the intact and functional prodrug (Fig. 2d), which displayed preferential killing of PSAsecreting cancer cells in-vitro (Fig. 3a-b). To further improve the selectivity of our platform, a PSAactivated prodrug was used as the cytotoxic payload rather than a standard chemotherapy agent to enhance selective toxicity to cells within the tumor microenvironment. This is because enzymatically active PSA is only present in the ECF of the tumor in men with advanced PCa ${ }^{24}$. Though PSA is used as a serum biomarker in men with PCa, it is enzymatically inactive in the blood due to incorrect processing or inhibition by ubiquitous serum protease inhibitors, such as $\alpha 1-\mathrm{AC}$ and $\alpha 2 \mathrm{M}^{24}$. Therefore, upon translating this platform for systemic administration, the prodrug will be selectively cleaved and thus activated only within the tumor microenvironment, potentially reducing systemic toxicity as a result of MSC trafficking to non-tumor tissue.

A further advantage of utilizing a thapsigargin-based prodrug (i.e. G114) in this platform stems from the non-selective toxicity of the parent compound and active drug moiety following PSA-mediated 
hydrolysis of the peptide substrate ${ }^{19,20,22}$. This inherent toxicity to all cells is derived from targeting a critical intracellular process (i.e. calcium homeostasis) essential to the viability of all cell types independent of AR expression and cell cycle status ${ }^{19,20,28,29,31}$. This latter point is particularly relevant to PCa, which is known to have a low proliferative index ${ }^{20}$. Additionally, PSA-mediated liberation of the active toxin the ECF of the tumor microenvironment leads to a 'bystander effect' that kills neighboring cells as a result of the non-selective mechanism of action of the active drug moiety. This has important implications for overcoming tumor heterogeneity and targeting advanced late-stage metastatic castration-resistant disease in which the emergence of AR-negative neuroendocrine or "small cell" phenotypes have been observed in a rare subset of patients. Importantly, up to one-half of these patients display a 'mixed' phenotype with features of both small cell and adenocarcinoma with elevated PSA levels ${ }^{58-61}$, suggesting the tumor remains heterogeneous even in this advanced setting with a subset of cells maintaining sufficient AR activity and PSA expression to drive a 'bystander effect'.

As shown in Fig. 1, we accomplished relatively high drug loading (>13\%) and encapsulation efficiency (>88\%). Furthermore, the encapsulated drug displayed sustained release from MPs and MP-loaded cells in-vitro, and is efficiently activated by PSA-secreting PCa cells, resulting in selective toxicity of G114 MPloaded MSCs against PSA-expressing cells in-vitro. Moreover, co-inoculation of G114 MP-loaded MSCs with CWR22 PCa cells at a high effector-to-target ratio ( $1 \times 10^{5} \mathrm{G} 114 \mathrm{MP}$-loaded MSCs to $1 \times 10^{6} \mathrm{PCa}$ cells) nearly eliminated tumor growth over the course of the assay and more than doubled TTP with dosedependent responses observed at lower MSC/PCa ratios (Fig. 4). The inhibition of tumor growth exhibited by blank-MP-loaded MSCs (which was still significantly lower than the impact of G11-MPloaded MSCs at the same dose) may be attributed to PLGA-induced inflammatory activation of macrophages ${ }^{62}$ or the previously reported anti-angiogenic effect of MSCs in other relevant cancer model ${ }^{63,64}$. An indirect effect on tumor growth via the microenvironment is supported by the in vitro data demonstrating the blank MPs themselves did not have any direct toxicity to the PCa cells (Fig. 3). 
Collectively, these data suggest that this MSC-based platform could deliver and activate therapeutically effective amounts of the prodrug if a sufficient number of cells infiltrated the tumor. Recently, Pessina et al. showed that MSCs pretreated with paclitaxel (PTX) releases the active PTX molecule inside microvesicles ${ }^{65,66}$. PTX-loaded MSCs (PTX-MSCs) were also shown to retain tropism towards cancer cells and display anti-cancer activities in a few cancer models ${ }^{67-69}$. While further strengthening the potential of using MSCs as drug delivery vehicles for cancer treatments, those studies use MSCs for delivery of the highly cytotoxic and non-specific PTX, known for its adverse effects when used in chemotherapy treatments of patients. The pretreatment approach, while simple, is short-lived and does not utilize a polymeric platform to encapsulate the drugs, thus lacking the platform flexibility of loading cells with different drug candidates (i.e., limited only to drugs that are spontaneously uptaken by cells upon pretreatment) and does not enable any control over the drug release kinetics.

Looking ahead, future studies will focus on successfully translating this cellular platform for systemic targeted delivery of anti-cancer drugs to sites of PCa metastasis. A key aspect towards achieving therapeutic efficacy of this platform would be to maximize the number of systemically infused drugdoped MSCs that reach sites of PCa metastasis. To accomplish this goal, bioengineering the cells for improved targeting to tumor sites will be used. For instance, incubating MSCs in conditioned supernatant from irradiated cancer cells can enhance tumor targeting by upregulating the expression of multiple chemokine receptors, including CCR2 ${ }^{70}$. HIF1-dependent upregulation of CXCL12 and CXCR4 in MSCs using preconditioning regimens including hypoxia, cobalt chloride and estrogen increase MSC trafficking to injured tissue ${ }^{71-74}$. Furthermore, we intend to explore multiple cell bioengineering approaches previously established in our laboratory such as surface chemical modification, mRNA transfection and small molecule pretreatment ${ }^{75,76}$ to express homing ligands on the cell surface and maximize targeting of systemically infused cells to sites of PCa metastasis. Finally, other cell types that 
internalize particles and display tropism to sites of cancer may also be used for drug delivery using the described PLGA MPs ${ }^{38}$.

A second strategy to further enhance the efficacy of this cell-based platform as a systemic treatment is to use a more selective and potent cytotoxic agent, thereby delivering therapeutically effective drug concentrations at lower ratios of infiltrating cells. An example of one such agent is the bacterial poreforming pro-toxin, proaerolysin, which induces cell lysis at low picomolar concentrations ${ }^{77-79}$. We have previously engineered the pro-toxin to be selectively activated by PSA using site-directed mutagenesis to replace the wildtype furin activation site with a PSA-selective peptide sequence ${ }^{79,80}$. While PSA-activated proaerolysin has proven to be very effective as a local therapy for benign prostatic hyperplasia (BPH) ${ }^{81,82}$, its usefulness as a systemic therapy is limited due to intrinsic limitations related to GPI-anchor binding and its mechanism of action, which prevent therapeutic concentrations from being achieved in target tissue following IV administration. These factors make it a promising candidate for further development as part of a cell-based delivery platform.

In this study, we report the development of G114 MP-loaded MSCs as a cellular drug delivery platform. This cellular platform releases significant amounts of prodrug and selectively induces death of PSAsecreting LNCaP cells in-vitro as well as inhibits tumor growth following co-inoculation in CWR22 xenografts. This study provides proof-of-principle evidence that MSCs can be used as 'Trojan Horse' delivery vehicles to overcome limitations related to systemic delivery of cytotoxic agents. Importantly, this hypothesis is the subject of an ongoing Phase 0 pre-prostatectomy clinical trial (NCT01983709) designed to quantify the number of systemically infused allogeneic human bone marrow-derived MSCs to sites of PCa, which will provide the baseline bounded conditions for the eventual clinical translation of the platform. Overall, MP-loaded cells emerge as promising candidates for the potential systemic treatment of metastatic PCa. 


\section{METHODS}

Creation of G114 MPs - A double emulsion approach was used to prepare G114-loaded PLGA MPs by modifying a previously established protocol ${ }^{38}$. Briefly, 50mg of PLGA [10kDa (50:50)], the encapsulating polymer, was dissolved into $5 \mathrm{~mL}$ of Dichloromethane (DCM), the organic solvent. Drug solution was prepared by dissolving G114 in Dimethyl sulfoxide (DMSO) and ultrapure $\mathrm{H}_{2} \mathrm{O}$. The PLGADCM solution was then homogenized, with dropwise addition of the drug solution. The emulsion was then homogenized two more times - once with 1\% PVA solution and then once with $0.3 \%$ PVA solution. The resultant emulsion was allowed to evaporate for 4 hours to remove the organic solvent component. After evaporation, the remaining PVA was removed via washing. The MP solution was centrifuged (3500rpm; $20 \mathrm{~min}$ ) to pellet the MPs and the supernatant containing PVA was aspirated. The pellet was then resuspended in distilled water for the next wash. This was repeated 3 times. For the final wash the pellet was resuspended in a small volume of ultrapure water, frozen at $-80^{\circ} \mathrm{C}$ and then lyophilized.

MP Size and Charge Determination - Dynamic light scattering was used to determine mean particle size and size polydispersity. $1 \mathrm{mg}$ of MPs was suspended into $2 \mathrm{~mL}$ of ultrapure water and placed into plastic cuvettes. The suspension was then sonicated and size measurements were performed using the Zetasizer (Malvern Instruments). The same solution used for particle size determination was then transferred to a zeta potential cuvette and analyzed via the Zetasizer.

Calculating drug loading and encapsulation efficiency in G114 MPs - MPs (1mg) were lysed overnight using $2 \mathrm{~mL}$ of $\mathrm{NaOH}-\mathrm{SDS}$. The solution was then subjected to a microBCA assay according to manufacturer instructions (Thermo Scientific). Plates were read using an Epoch Microplate Spectrophotometer (Bio-Tek). Using the standard curve of the free drug, the concentration of drug in the lysed MPs was extrapolated and used to calculate the drug loading in the G114-MPs (mass of drug out of total MP mass) and the encapsulation efficiency (amount of drug successfully encapsulated out of initial amount of drug used in the fabrication process). 
Cell Culture - Human bone marrow-derived MSCs were obtained from Rooster Bio, Inc. (Frederick, MD). LNCaP and MDA-MB-231 cells were obtained from ATCC (Manassas, VA). MSCs were cultured in hMSC High Performance Media (Rooster Bio) according to manufacturer's recommendations to achieve sufficient numbers of cells for in vivo studies as previously described ${ }^{83}$. LNCaP were cultured in RPMI-1640 medium supplemented with 10\% FBS, 1\% L-glutamine, and 1\% penicillin-streptomycin. MDA-MB-231 cells were cultured in DMEM supplemented with $10 \%$ FBS, $1 \%$ L-glutamine, and $1 \%$ penicillin-streptomycin. All cells were cultured in a $5 \% \mathrm{CO}_{2}, 95 \%$ air humidified incubator at $37^{\circ} \mathrm{C}$.

Loading MSCs with MPs - For MP internalization into MSCs, MPs were resuspended in MEM- $\alpha$ media (1\% FBS) at $0.1 \mathrm{mg} / \mathrm{mL}$ and sonicated to disrupt potential aggregates. MSCs were then incubated with the MP solution for $15 \mathrm{~h}$, and then washed 3 times with PBS to remove any MP residues prior to performing the different assays described (i.e., imaging, supernatant collection, co-culture with cancer cells or XTT assay to assess MSC viability).

Assessing MP Internalization into MSCs via Flow Cytometry and Confocal Microscopy - To assess MP internalization by MSCs, MPs loaded with Dil (vibrant membrane dye, Invitrogen) were fabricated using the double emulsion process. These particles were then internalized into MSCs overnight. The cells were washed with PBS, trypsinized and centrifuged (3500rpm, $5 \mathrm{~min})$. The cell pellet was then resuspended in 200uL PBS (supplemented with 0.1\% BSA). An Accuri C6 flow cytometer was used to determine the presence of fluorescent cells, indicating cell interaction with the dye-loaded MPs.

Confocal Microscope was used to confirm MPs were successfully internalized into MSCs. MSCs were loaded with Dil MPs as described and then washed and trypsinized. After centrifugation and supernatant aspiration, cells were resuspended in $100 \mathrm{uL}$ of PBS with $1 \mu \mathrm{g} / \mathrm{mL}$ Hoechst and $5 \mu \mathrm{L} / \mathrm{mL}$ Cholera toxin for nuclear and membrane staining, respectively. Cells were incubated in the staining solution on ice for 15 minutes and then placed onto fibronectin-coated glass slides and allowed to 
adhere for $5 \mathrm{~min}$ at $37^{\circ} \mathrm{C}$. Next, cells were fixed in $4 \%$ paraformaldehyde. Olympus FV1200 confocal microscopy was then used to image the cells and the MPs.

MSC immunophenotyping - MSC surface expression of the cell membrane markers, CD44, CD73, CD90, CD105, CD45 and HLA-DR upon cell incubation with blank MPs or G114-MPs was examined via flow cytometry using fluorescently-conjugated antibodies for the indicated markers.

Release Kinetics studies - To assess drug release from G114-MPs, MPs (2.5mg) were suspended in $1.25 \mathrm{~mL}$ MEM- $\alpha$ media (supplemented with $10 \% \mathrm{FBS}$ ). Tubes were placed in a $37^{\circ} \mathrm{C}$ shaker and at each time point, tubes were centrifuged $(15 \mathrm{~min}, 3500 \mathrm{rpm})$ to pellet out the MPs, with $1 \mathrm{~mL}$ of the supernatant then carefully extracted and replaced with $1 \mathrm{~mL}$ of fresh media. LCMS was then used on the extracted supernatant to determine the concentration of the released drug at each time point.

To assess drug release from G114-MP-loaded MSCs, cells (5X104/well in a 6 well plate) were incubated with G114-MPs (15h, $0.1 \mathrm{mg} / \mathrm{mL}$ in $1 \%$ FBS-supplemented MEM- $\alpha$ media), washed and then fresh $10 \%$ FBS-supplemented MEM- $\alpha$ media was applied. At each time point, media was collected and replaced with fresh media. G114 concentration at each time point was measured via LCMS. Importantly, no differentiation was observed over the course of the study in response to serum supplementation.

Effect of MP-loaded MSCs on cancer cell viability - Following MP loading into MSCs $\left(5 \times 10^{4} /\right.$ well in a 12 well plate) as described, the media was changed into full RPMI media (10\%FBS, 1\% L-Glutamine, 1\% Penicillin-Streptomycin), in which MP-loaded MSCs were cultured for 3 days. Media was then transferred onto LNCaP or MDA-MB-231 cancer cells (5X10 / well in a 12 well plate). After 3 days of incubation, XTT was performed to determine cancer cell viability in response to supernatant from MPloaded MSCs. For co-culture experiments, transwell inserts $(0.4 \mu \mathrm{m}$ pore size polycarbonate membrane in a 12 well plate) were coated with fibronectin $(20 \mathrm{ng} / \mathrm{mL})$ and MSCs were then seeded onto the inserts $\left(5 \times 10^{4}\right.$ cells/transwell). In parallel, LNCaP or MDA-MB cancer cells were plated in a 12 well plate (5X10\%/well). Following 24h (allowing MSCs to attach), MPs were loaded into the MSCs as described. 
Next, MSC-loaded transwell inserts were placed onto wells already seeded with the cancer cells. MSCs were co-cultured with the cancer cells for 3 days and the impact of G114-MP-loaded MSCs on cancer cell viability was measured via XTT.

Determination of pro- and active drug concentrations by LCMS - Calibration standards consisting of prodrug G114 (MW = 1684), L12ADT (MW = 890), and 12ADT (MW = 777) are prepared as 10x final concentration in $50 \%$ acetonitrile/water $0.1 \%$ formic acid (FA). The process was performed on ice with chilled reagents in $1.5 \mathrm{~mL}$ microfuge tubes. Five microliters of these respective standards were added into $50 \mu \mathrm{L}$ control mouse plasma or homogenized tissue along with $5 \mu \mathrm{L}$ of the Internal Standard (IS)[1 $\mu \mathrm{M}$ S12ADT $(\mathrm{MW}=864)]$, deproteinated with $150 \mu \mathrm{L}$ acetonitrile/0.1\% FA, and then centrifuged. Five microliters of IS was added to $50 \mu \mathrm{L}$ plasma or tissue homogenate samples from treated mice and these samples were processed as above. The resulting supernatants were analyzed by liquid chromatography coupled to an electrospray triple quadrupole mass spectrometer (1100 series HPLC Agilent, API 3000 Mass Spec; ABSciex) according to previously described methods ${ }^{84}$. The turbo ion spray nebulizer settings included nebulizer gas set at $10 \mathrm{~mL} / \mathrm{min}$ and ion spray potential of $5500 \mathrm{~V}$. The drying gas temperature was set at $450^{\circ} \mathrm{C}$ and its flow at $800 \mathrm{~mL} / \mathrm{min}$. A linear gradient elution HPLC method was used to separate G114 from the active drugs L12ADT or 12ADT and IS with a mobile phase composed of 5\% acetonitrile/water/0.1\% FA (solvent A) and 100\% acetonitrile/0.1\% FA (solvent B). The initial conditions were $60 \%$ solvent $A / 40 \%$ solvent $B$ at a flow rate of $0.25 \mathrm{~mL} / \mathrm{min}$. The injection volume was $10 \mu \mathrm{l}$, and at 1 min post-injection, a linear gradient raised the mobile phase composition to $100 \%$ solvent $B$ by 7 min with a return to initial conditions at 9 min. Separation was carried out using a $150 \times 2.1 \mathrm{~mm}$, 3.5micron reversed phase column (Waters Xterra, pn 186000410). Detection was performed in positive MRM (Multiple Reaction Monitoring) mode looking for the transition pairs of $G 114$ (M/Z=843/136), L12ADT (891/216), 12ADT $(778 / 198)$ and IS $(865 / 216)$. The respective retention times for these compounds were $7.25,8.05,7.85$, and $7.77 \mathrm{~min}$. The calibration range of the standards in both control 
plasma and tissues was 0.001-10 $\mu \mathrm{M}$. Linear regression analysis was used to generate best-fit lines, from which peak areas of samples were converted to concentration of the respective analyte.

In-vivo efficacy studies - All animal studies were performed in accordance with protocols reviewed and approved by the Animal Care and Use Committee of the Johns Hopkins University School of Medicine. A male athymic nude mouse bearing the CWR22 PCa xenograft was euthanized with an overdose of $\mathrm{CO}_{2}$. Using sterile instruments the tumor was excised and transferred to a sterile petri dish. The tumor was minced in PBS with two scalpel blades and digested into a single cell suspension using a tumor dissociation kit (Miltenyi) and gentleMACS dissociator (Miltenyi). Viable cells were determined via trypan blue exclusion. $1 \times 10^{6} \mathrm{CWR} 22$ cells were resuspended with MSCs (untreated, blank MP-loaded or G114 MP-loaded) at doses ranging from $1 \times 10^{3}$ to $1 \times 10^{5} \mathrm{MSCs} / 1 \times 10^{6} \mathrm{CWR} 22$ in $200 \mu \mathrm{l}$ Matrigel/HBSS (50/50). Cell suspensions were inoculated subcutaneously into recipient 6 wk old male athymic nude mice. This was repeated in two independent experiments with 4 animals/group/experiment, the second set of which had bilateral tumors for a total of 12 tumors/group. Body weight and tumor measurements were made $3 x /$ week using calipers, and the tumor volume $\left(\mathrm{cm}^{3}\right)$ was calculated using the following formula: $0.5236 \times \mathrm{L} \times \mathrm{W} \times \mathrm{H}$. Tumor-bearing animals were defined as having a measurable tumor $\geq 0.05 c \mathrm{c}$ for 2 consecutive measurements, and time to progression (TTP) was defined as $\geq 50 \%$ tumor-bearing animals. The mice were euthanized by $\mathrm{CO}_{2}$ overdose at the end of the study in accordance with the approved protocol.

Statistical Analysis - Linear mixed effect models were used to model the changes in tumor size over time and to compare each treatment group with untreated controls in terms of tumor growth rate. Time-by-group interaction was tested and a significant interaction would imply that the rate of tumor growth is different in two groups. Log transformation was applied to the tumor size outcome when fitting these models so that the time curves were linear. Furthermore, at each time point, nonparametric Wilcoxon exact test was used to compare the tumor sizes between treatment groups. Time 
to tumor progression was defined as the time from tumor inoculation to the point when tumors grew to $>0.05 \mathrm{cc}$. Kaplan-Meier curves were plotted to describe time to tumor progression, and log rank tests were used to compare between treatment groups. All tests were two-sided and $p$ values $p$ values $<0.05$ were considered to indicate statistical significance. The analysis was performed using SAS software (version 9.4, Cary, NC).

\section{ACKNOWLEDGEMENTS}

This work was supported by National Institute of Health grant HL095722 to J.M.K.; The Charles A. King Trust Fellowship to O.L.; The William Randolph Hearst BWH DOM Young Investigator Award to O.L.; a Prostate Cancer Foundation Young Investigator Award to W.N.B.; NIH-Prostate SPORE Grant P50 CA058236 to S.R.D. and J.T.I.; Department of Defense Synergy Grant W81XWH-13-1-0304 to J.M.K., S.R.D., and J.T.I.; and by a Movember Prostate Cancer Foundation Challenge Award to S.R.D, J.T.I and J.M.K.

\section{FIGURE LEGENDS}

Scheme 1: Mesenchymal stem cells doped with drug-loaded PLGA microparticles as a potential cellbased treatment for prostate cancer.

Figure 1: Properties of G114-loaded PLGA MPs. (a) G114 pro-drug and its PSA-induced cleavage into the active toxin Leu-12ADT ( $\mu$ denotes a morpholino cap, which is incorporated to prevent aminopeptidase hydrolysis and activation). (b) Physical and loading properties of G114-loaded MPs. To determine drug loading in the G114-MPs (mass of drug out of total MP mass) and the encapsulation efficiency (amount of drug encapsulated in MPs out of the initial amount of drug used in the MP production process), MPs were lysed overnight using NaOH-SDS, and G114 levels were measured using a microBCA assay). (c) SEM images of empty and G114-loaded MPs (top panels: X7840, scale bar is $2 \mu \mathrm{m}$, bottom panels: X14320, 
scale bar is $1 \mu \mathrm{m}$ ). (d) Release kinetics of G114 from G114-loaded PLGA MPs (2.5mg MPs incubated in 10\% FBS-supplemented $1 \mathrm{~mL}$ MEM- $\alpha$, media replaced at indicated time points and analyzed via LCMS).

Figure 2: PLGA MPs are internalized by MSCs, followed by sustained release of intact G114 from G114MP-loaded cells. (a) MSCs were incubated with PLGA MPs (blank MPs or G114-MPs at 0.1mg/mL for 16h), followed by assessment of cell viability via XTT (*p<0.05 vs. untreated control, one-way ANOVA using Tukey's HSD, error bars represent SD). (b-c) Dil-loaded PLGA MPS, with similar properties to prodrug MPs, were incubated $(0.1 \mathrm{mg} / \mathrm{mL}$ ) overnight with MSCs and flow cytometry analysis (b) and confocal microscopy (c) were performed to detect MP uptake and internalization by MSCs (red (Dil) - MPs, green (cholera toxin) - cell membrane, blue (Hoechst) - cell nucleus). (d) To assess drug release from

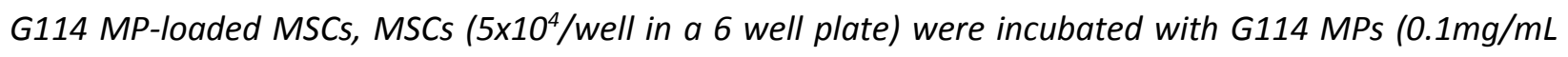
MPs for 15h) and media (10\% FBS-supplemented MEM- $\alpha$ ) was collected at indicated time points and analyzed by LCMS for the presence of the intact G114 pro-drug and the free active toxins (L12ADT/12ADT).

\section{Figure 3: G114 released by G114 MP-loaded MSCs is effective in preferentially killing PSA-secreting}

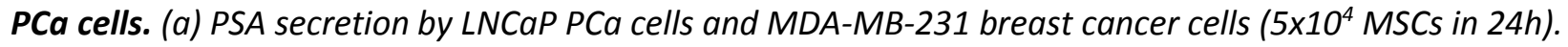
(b) Following incubation of MSCs $\left(5 \times 10^{4}\right.$ cells) with G114 MPs $(0.1 \mathrm{mg} / \mathrm{mL}$, 16hours), media was replaced, collected after $72 h$ and then applied on LNCaP PCa cells and MDA-MB-231 breast cancer cells for $72 h$. Cancer cell viability was then tested via XTT (n.s - LNCaP vs. MDA-MB statistically insignificant. * $p<0.05$ supernatant from G114-MP MSC treatment statistically significant vs. other indicated treatments, one-

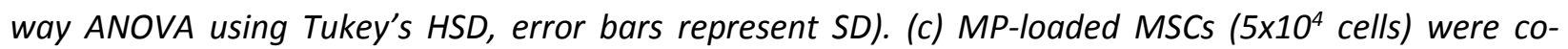
cultured in a transwell system $(0.4 \mu \mathrm{m})$ in the presence of LNCaP or MDA-MB-231 cells $\left(5 \times 10^{4}\right.$ cells) for $72 h$, followed by XTT analysis to assess cancer cell viability (n.s - LNCaP vs MDA-MB statistically insignificant. ${ }^{*} p<0.05$ co-culture with G114-MP MSCs statistically significant vs. other indicated groups, one-way ANOVA using Tukey's HSD, error bars represent SD).

Figure 4: In-vivo activity of G114 MP-loaded MSCs. (a) The predicted bioequivalent dose of G114 MPloaded MSCS vs. intravenously (IV) administered G114 at the maximum tolerated dose (MTD). (Right) Based upon the G114 release kinetics, the predicted intra-tumoral concentration of G114 delivered at different doses of MSCs co-inoculated with $1 \times 10^{6}$ PCa cells (in a 200 $\mathrm{LL}$ volume) was calculated (ranging from $1 \times 10^{3}$ to $1 \times 10^{5}$ G114 MP-MSCs per $1 \times 10^{6} \mathrm{PCa}$ cells). The intra-tumoral concentration of G114 when delivered intravenously (IV) at the MTD (i.e. $7 \mathrm{mg} / \mathrm{kg}$ ) is $640 \mathrm{nM}^{21}$. (Left) The predicted fold increase in the intra-tumoral concentration of G114 produced at these MSC doses over that achieved when G114 is 
delivered IV at the MTD. The bioequivalent dose (i.e. $640 \mathrm{nM}$ ) is predicted at a dose of $2 \times 10^{3} \mathrm{G} 114 \mathrm{MP}$ loaded MSCs per $1 \times 10^{6} \mathrm{PCa}$ cells. 5- to 50-times more G114 is predicted to be delivered at the $1 \times 10^{4}$ and $1 \times 10^{5}$ MSC doses, respectively, than can be achieved at the systemically-administered MTD. (b) $1 \times 10^{6}$ CWR22 PCa cells were co-inoculated with blank- or G114 MP-loaded MSCs at the indicated doses in 200 $\mu$ l Matrigel/HBSS (50:50) into male athymic nude mice. Tumor volume was measured 3x/wk. Figure is the composite of two independent experiments $\left({ }^{*} p<0.005\right.$ relative to untreated control, ${ }^{\wedge} p<0.05$ relative to Blank MP-loaded MSC). (c) The probability of tumor-free survival over time. (d) G114 MPloaded MSCs improve time to progression (TTP) in-vivo. The median number of days post-inoculation required to reach the TTP endpoint. TTP defined as $\geq 50 \%$ of animals in a group bearing a tumor ( $\geq 0.05 c c)$. Fold improvement relative to the untreated control and the $1 \times 10^{5}$ dose of blank MP-loaded MSC groups were calculated (^NE: not estimable. Median time was not reached because less than half of the mice developed tumors under this condition. $\left.{ }^{*} p=0.012 ;{ }^{* *} p=0.003 ;{ }^{* * *} p<0.0001\right)$.(e) Percent change in baseline body weight following the different treatments (all treatments had an insignificant effect on body weight).

\section{REFERENCES}

(1) Briganti, A.; Suardi, N.; Gallina, A.; Abdollah, F.; Novara, G.; Ficarra, V.; Montorsi, F. Predicting the Risk of Bone Metastasis in Prostate Cancer. Cancer Treat. Rev. 2014, 40, $3-11$.

(2) Cooper, C. R.; Chay, C. H.; Pienta, K. J. The Role of alpha(v)beta(3) in Prostate Cancer Progression. Neoplasia 2002, 4, 191-194.

(3) Jin, J.-K.; Dayyani, F.; Gallick, G. E. Steps in Prostate Cancer Progression That Lead to Bone Metastasis. Int. J. Cancer 2011, 128, 2545-2561.

(4) Agarwal, N.; Di Lorenzo, G.; Sonpavde, G.; Bellmunt, J. New Agents for Prostate Cancer. Ann Oncol 2014.

(5) Dayyani, F.; Gallick, G. E.; Logothetis, C. J.; Corn, P. G. Novel Therapies for Metastatic Castrate-Resistant Prostate Cancer. J. Natl. Cancer Inst. 2011, 103, 1665-1675.

(6) Lin, J.; Sinibaldi, V. J.; Carducci, M. A.; Denmeade, S.; Song, D.; Deweese, T.; Eisenberger, M. A. Phase I Trial with a Combination of Docetaxel and ${ }^{153} \mathrm{Sm}$-Lexidronam 
in Patients with Castration-Resistant Metastatic Prostate Cancer. Urol. Oncol. 29, 670675.

(7) Oudard, S. Progress in Emerging Therapies for Advanced Prostate Cancer. Cancer Treat. Rev. 2013, 39, 275-289.

(8) Roth, J. C.; Curiel, D. T.; Pereboeva, L. Cell Vehicle Targeting Strategies. Gene Ther 2008, 15, 716-729.

(9) Peer, D.; Karp, J. M.; Hong, S.; Farokhzad, O. C.; Margalit, R.; Langer, R. Nanocarriers as an Emerging Platform for Cancer Therapy. Nat. Nanotechnol. 2007, 2, 751-760.

(10) Ernsting, M. J.; Murakami, M.; Roy, A.; Li, S.-D. Factors Controlling the Pharmacokinetics, Biodistribution and Intratumoral Penetration of Nanoparticles. $J$. Control. Release 2013, 172, 782-794.

(11) Dawidczyk, C. M.; Kim, C.; Park, J. H.; Russell, L. M.; Lee, K. H.; Pomper, M. G.; Searson, P. C. State-of-the-Art in Design Rules for Drug Delivery Platforms: Lessons Learned from FDA-Approved Nanomedicines. J. Control. Release 2014, 187, 133-144.

(12) Wong, C.; Stylianopoulos, T.; Cui, J.; Martin, J.; Chauhan, V. P.; Jiang, W.; Popovic, Z.; Jain, R. K.; Bawendi, M. G.; Fukumura, D. Multistage Nanoparticle Delivery System for Deep Penetration into Tumor Tissue. Proc. Natl. Acad. Sci. U. S. A. 2011, 108, 24262431.

(13) Chauhan, V. P.; Jain, R. K. Strategies for Advancing Cancer Nanomedicine. Nat. Mater. 2013, 12, 958-962.

(14) Brennen, W. N.; Denmeade, S. R.; Isaacs, J. T. Mesenchymal Stem Cells as a Vector for the Inflammatory Prostate Microenvironment. Endocr. Relat. Cancer 2013, 20, R269R290.

(15) Brennen, W. N.; Chen, S.; Denmeade, S. R.; Isaacs, J. T. Quantification of Mesenchymal Stem Cells (MSCs) at Sites of Human Prostate Cancer. Oncotarget 2013, 4, 106-117.

(16) Kidd, S.; Spaeth, E.; Dembinski, J. L.; Dietrich, M.; Watson, K.; Klopp, A.; Battula, V. L.; Weil, M.; Andreeff, M.; Marini, F. C. Direct Evidence of Mesenchymal Stem Cell Tropism for Tumor and Wounding Microenvironments Using in Vivo Bioluminescent Imaging. Stem Cells 2009, 27, 2614-2623.

(17) Ankrum, J.; Karp, J. M. Mesenchymal Stem Cell Therapy: Two Steps Forward, One Step Back. Trends Mol. Med. 2010, 16, 203-209.

(18) Ankrum, J. a; Ong, J. F.; Karp, J. M. Mesenchymal Stem Cells: Immune Evasive, Not Immune Privileged. Nat. Biotechnol. 2014, 32, 252-260. 
(19) Vander Griend, D. J.; Antony, L.; Dalrymple, S. L.; Xu, Y.; Christensen, S. B.; Denmeade, S. R.; Isaacs, J. T. Amino Acid Containing Thapsigargin Analogues Deplete Androgen Receptor Protein via Synthesis Inhibition and Induce the Death of Prostate Cancer Cells. Mol. Cancer Ther. 2009, 8, 1340-1349.

(20) Denmeade, S. R.; Jakobsen, C. M.; Janssen, S.; Khan, S. R.; Garrett, E. S.; Lilja, H.; Christensen, S. B.; Isaacs, J. T. Prostate-Specific Antigen-Activated Thapsigargin Prodrug as Targeted Therapy for Prostate Cancer. J. Natl. Cancer Inst. 2003, 95, 990-1000.

(21) Jakobsen, C. M.; Denmeade, S. R.; Isaacs, J. T.; Gady, A.; Olsen, C. E.; Christensen, S. B. Design, Synthesis, and Pharmacological Evaluation of Thapsigargin Analogues for Targeting Apoptosis to Prostatic Cancer Cells. J Med Chem 2001, 44, 4696-4703.

(22) Denmeade, S. R.; Isaacs, J. T. Engineering Enzymatically Activated "Molecular Grenades" for Cancer. Oncotarget 2012, 3, 666-667.

(23) Brawley, O. W. Prostate Cancer Epidemiology in the United States. World J. Urol. 2012, 30, 195-200.

(24) Denmeade, S. R.; Sokoll, L. J.; Chan, D. W.; Khan, S. R.; Isaacs, J. T. Concentration of Enzymatically Active Prostate-Specific Antigen (PSA) in the Extracellular Fluid of Primary Human Prostate Cancers and Human Prostate Cancer Xenograft Models. Prostate 2001, 48, 1-6.

(25) Williams, S. A.; Singh, P.; Isaacs, J. T.; Denmeade, S. R. Does PSA Play a Role as a Promoting Agent during the Initiation And/or Progression of Prostate Cancer? Prostate 2007, 67, 312-329.

(26) Williams, S. A.; Jelinek, C. A.; Litvinov, I.; Cotter, R. J.; Isaacs, J. T.; Denmeade, S. R. Enzymatically Active Prostate-Specific Antigen Promotes Growth of Human Prostate Cancers. Prostate 2011, 71, 1595-1607.

(27) Denmeade, S. R.; Lou, W.; Lovgren, J.; Malm, J.; Lilja, H.; Isaacs, J. T. Specific and Efficient Peptide Substrates for Assaying the Proteolytic Activity of Prostate-Specific Antigen. Cancer Res 1997, 57, 4924-4930.

(28) Denmeade, S. R.; Isaacs, J. T. The SERCA Pump as a Therapeutic Target: Making a "Smart Bomb" for Prostate Cancer. Cancer Biol. Ther. 2005, 4, 14-22.

(29) Tombal, B.; Weeraratna, A. T.; Denmeade, S. R.; Isaacs, J. T. Thapsigargin Induces a Calmodulin/calcineurin-Dependent Apoptotic Cascade Responsible for the Death of Prostatic Cancer Cells. Prostate 2000, 43, 303-317.

(30) Brøgger Christensen, S.; Andersen, A.; Kromann, H.; Treiman, M.; Tombal, B.; Denmeade, S.; Isaacs, J. T. Thapsigargin Analogues for Targeting Programmed Death of Androgen-Independent Prostate Cancer Cells. Bioorg. Med. Chem. 1999, 7, 1273-1280. 
(31) Lin, X. S.; Denmeade, S. R.; Cisek, L.; Isaacs, J. T. Mechanism and Role of Growth Arrest in Programmed (apoptotic) Death of Prostatic Cancer Cells Induced by Thapsigargin. Prostate 1997, 33, 201-207.

(32) Christensen, S. B.; Skytte, D. M.; Denmeade, S. R.; Dionne, C.; Møller, J. V.; Nissen, P.; Isaacs, J. T. A Trojan Horse in Drug Development: Targeting of Thapsigargins towards Prostate Cancer Cells. Anticancer. Agents Med. Chem. 2009, 9, 276-294.

(33) Jain, R. A. The Manufacturing Techniques of Various Drug Loaded Biodegradable Poly(lactide-Co-Glycolide) (PLGA) Devices. Biomaterials 2000, 21, 2475-2490.

(34) Jain, R. A.; Rhodes, C. T.; Railkar, A. M.; Malick, A. W.; Shah, N. H. Comparison of Various Injectable Protein-Loaded Biodegradable Poly(lactide-Co-Glycolide) (PLGA) Devices: In-Situ-Formed Implant versus in-Situ-Formed Microspheres versus Isolated Microspheres. Pharm Dev Technol 2000, 5, 201-207.

(35) Jain, R. K.; Stylianopoulos, T. Delivering Nanomedicine to Solid Tumors. Nat. Rev. Clin. Oncol. 2010, 7, 653-664.

(36) Sarkar, D.; Ankrum, J. a; Teo, G. S. L.; Carman, C. V; Karp, J. M. Cellular and Extracellular Programming of Cell Fate through Engineered Intracrine-, Paracrine-, and Endocrine-like Mechanisms. Biomaterials 2011, 32, 3053-3061.

(37) Ankrum, J. A.; Dastidar, R. G.; Ong, J. F.; Levy, O.; Karp, J. M. Performance-Enhanced Mesenchymal Stem Cells via Intracellular Delivery of Steroids. Sci. Rep. 2014, 4, 4645.

(38) Ankrum, J. A.; Miranda, O. R.; Ng, K. S.; Sarkar, D.; Xu, C.; Karp, J. M. Engineering Cells with Intracellular Agent-Loaded Microparticles to Control Cell Phenotype. Nat. Protoc. 2014, 9, 233-245.

(39) Cohen, S.; Yoshioka, T.; Lucarelli, M.; Hwang, L. H.; Langer, R. Controlled Delivery Systems for Proteins Based on Poly(lactic/glycolic Acid) Microspheres. Pharm Res 1991, 8, 713-720.

(40) Thomas, T. T.; Kohane, D. S.; Wang, A.; Langer, R. Microparticulate Formulations for the Controlled Release of Interleukin-2. J. Pharm. Sci. 2004, 93, 1100-1109.

(41) Brandy, Y.; Ononiwu, I.; Adedeji, D.; Williams, V.; Mouamba, C.; Kanaan, Y.; Copeland, R. L.; Wright, D. A.; Butcher, R. J.; Denmeade, S. R.; et al. Synthesis and Cytotoxic Activities of Some 2-arylnaphtho[2,3-D]oxazole-4,9-Dione Derivatives on AndrogenDependent (LNCaP) and Androgen-Independent (PC3) Human Prostate Cancer Cell Lines. Invest. New Drugs 2012, 30, 1709-1714.

(42) Cailleau, R.; Young, R.; Olivé, M.; Reeves, W. J. Breast Tumor Cell Lines from Pleural Effusions. J. Natl. Cancer Inst. 1974, 53, 661-674. 
(43) Dalrymple, S. L.; Becker, R. E.; Isaacs, J. T. The Quinoline-3-Carboxamide AntiAngiogenic Agent, Tasquinimod, Enhances the Anti-Prostate Cancer Efficacy of Androgen Ablation and Taxotere without Effecting Serum PSA Directly in Human Xenografts. Prostate 2007, 67, 790-797.

(44) Leibowitz-Amit, R.; Templeton, A. J.; Alibhai, S. M.; Knox, J. J.; Sridhar, S. S.; Tannock, I. F.; Joshua, A. M. Efficacy and Toxicity of Abiraterone and Docetaxel in Octogenarians with Metastatic Castration-Resistant Prostate Cancer. J. Geriatr. Oncol. 2015, 6, 23-28.

(45) Kellokumpu-Lehtinen, P. L.; Hjalm-Eriksson, M.; Thellenberg-Karlsson, C.; Astrom, L.; Franzen, L.; Marttila, T.; Seke, M.; Taalikka, M.; Ginman, C. Toxicity in Patients Receiving Adjuvant Docetaxel + Hormonal Treatment after Radical Radiotherapy for Intermediate or High-Risk Prostate Cancer: A Preplanned Safety Report of the SPCG-13 Trial. Prostate Cancer Prostatic Dis 2012, 15, 303-307.

(46) Pridgen, E. M.; Langer, R.; Farokhzad, O. C. Biodegradable, Polymeric Nanoparticle Delivery Systems for Cancer Therapy. Nanomedicine (Lond). 2007, 2, 669-680.

(47) Fassas, A.; Buffels, R.; Kaloyannidis, P.; Anagnostopoulos, A. Safety of High-Dose Liposomal Daunorubicin (daunoxome) for Refractory or Relapsed Acute Myeloblastic Leukaemia. Br. J. Haematol. 2003, 122, 161-163.

(48) Safra, T.; Muggia, F.; Jeffers, S.; Tsao-Wei, D. D.; Groshen, S.; Lyass, O.; Henderson, R.; Berry, G.; Gabizon, A. Pegylated Liposomal Doxorubicin (doxil): Reduced Clinical Cardiotoxicity in Patients Reaching or Exceeding Cumulative Doses of $500 \mathrm{mg} / \mathrm{m} 2$. Ann Oncol 2000, 11, 1029-1033.

(49) Maeda, H. The Enhanced Permeability and Retention (EPR) Effect in Tumor Vasculature: The Key Role of Tumor-Selective Macromolecular Drug Targeting. Adv. Enzyme Regul. 2001, 41, 189-207.

(50) Alexis, F.; Pridgen, E.; Molnar, L. K.; Farokhzad, O. C. Factors Affecting the Clearance and Biodistribution of Polymeric Nanoparticles. Mol. Pharm. 2008, 5, 505-515.

(51) Owens, D. E.; Peppas, N. a. Opsonization, Biodistribution, and Pharmacokinetics of Polymeric Nanoparticles. Int. J. Pharm. 2006, 307, 93-102.

(52) Gjorgieva, D.; Zaidman, N.; Bosnakovski, D. Mesenchymal Stem Cells for Anti-Cancer Drug Delivery. Recent Pat. Anticancer. Drug Discov. 2013, 8, 310-318.

(53) Roger, M.; Clavreul, A.; Venier-Julienne, M. C.; Passirani, C.; Sindji, L.; Schiller, P.; Montero-Menei, C.; Menei, P. Mesenchymal Stem Cells as Cellular Vehicles for Delivery of Nanoparticles to Brain Tumors. Biomaterials 2010, 31, 8393-8401.

(54) Dwyer, R. M.; Kerin, M. J. Mesenchymal Stem Cells and Cancer: Tumor-Specific Delivery Vehicles or Therapeutic Targets? Hum Gene Ther 2010, 21, 1506-1512. 
(55) Gao, Z.; Zhang, L.; Hu, J.; Sun, Y. Mesenchymal Stem Cells: A Potential TargetedDelivery Vehicle for Anti-Cancer Drug, Loaded Nanoparticles. Nanomedicine Nanotechnology, Biol. Med. 2013, 9, 174-184.

(56) Xu, C.; Mu, L.; Roes, I.; Miranda-Nieves, D.; Nahrendorf, M.; Ankrum, J. a; Zhao, W.; Karp, J. M. Nanoparticle-Based Monitoring of Cell Therapy. Nanotechnology 2011, 22, 494001.

(57) Xu, C.; Miranda-Nieves, D.; Ankrum, J. a.; Matthiesen, M. E.; Phillips, J. a.; Roes, I.; Wojtkiewicz, G. R.; Juneja, V.; Kultima, J. R.; Zhao, W.; et al. Tracking Mesenchymal Stem Cells with Iron Oxide Nanoparticle Loaded Poly(lactide-Co-Glycolide)

Microparticles. Nano Lett. 2012, 12, 4131-4139.

(58) Shah, R. B.; Mehra, R.; Chinnaiyan, A. M.; Shen, R.; Ghosh, D.; Zhou, M.; Macvicar, G. R.; Varambally, S.; Harwood, J.; Bismar, T. A.; et al. Androgen-Independent Prostate Cancer Is a Heterogeneous Group of Diseases: Lessons from a Rapid Autopsy Program. Cancer Res. 2004, 64, 9209-9216.

(59) Nadal, R.; Schweizer, M.; Kryvenko, O. N.; Epstein, J. I.; Eisenberger, M. A. Small Cell Carcinoma of the Prostate. Nat. Rev. Urol. 2014, 11, 213-219.

(60) Aparicio, A. M.; Harzstark, A. L.; Corn, P. G.; Wen, S.; Araujo, J. C.; Tu, S.-M.; Pagliaro, L. C.; Kim, J.; Millikan, R. E.; Ryan, C.; et al. Platinum-Based Chemotherapy for Variant Castrate-Resistant Prostate Cancer. Clin. Cancer Res. 2013, 19, 3621-3630.

(61) Aygun, C. Small Cell Carcinoma of the Prostate: A Case Report and Review of the Literature. Md. Med. J. 1997, 46, 353-356.

(62) Nicolete, R.; dos Santos, D. F.; Faccioli, L. H. The Uptake of PLGA Micro or Nanoparticles by Macrophages Provokes Distinct in Vitro Inflammatory Response. Int. Immunopharmacol. 2011, 11, 1557-1563.

(63) Menge, T.; Gerber, M.; Wataha, K.; Reid, W.; Guha, S.; Cox, C. S.; Dash, P.; Reitz, M. S.; Khakoo, A. Y.; Pati, S. Human Mesenchymal Stem Cells Inhibit Endothelial Proliferation and Angiogenesis via Cell-Cell Contact Through Modulation of the VECadherin/ $\beta$-Catenin Signaling Pathway. Stem Cells Dev. 2012, 22, 120626080437008.

(64) Otsu, K.; Das, S.; Houser, S. D.; Quadri, S. K.; Bhattacharya, S.; Bhattacharya, J. Concentration-Dependent Inhibition of Angiogenesis by Mesenchymal Stem Cells. Blood 2009, 113, 4197-4205.

(65) Mariotti, M.; Colognato, R.; Rimoldi, M.; Rizzetto, M.; Sisto, F.; Cocce, V.; Bonomi, A.; Parati, E.; Alessandri, G.; Bagnati, R.; et al. Mesenchymal Stromal Cells Uptake and Release Paclitaxel without Reducing Its Anticancer Activity. Anticancer. Agents Med. Chem. 2015, 15, 400-405. 
(66) Pascucci, L.; Coccè, V.; Bonomi, A.; Ami, D.; Ceccarelli, P.; Ciusani, E.; Viganò, L.; Locatelli, A.; Sisto, F.; Doglia, S. M.; et al. Paclitaxel Is Incorporated by Mesenchymal Stromal Cells and Released in Exosomes That Inhibit in Vitro Tumor Growth: A New Approach for Drug Delivery. J. Control. Release 2014, 192, 262-270.

(67) Pacioni, S.; D’Alessandris, Q. G.; Giannetti, S.; Morgante, L.; De Pascalis, I.; Coccè, V.; Bonomi, A.; Pascucci, L.; Alessandri, G.; Pessina, A.; et al. Mesenchymal Stromal Cells Loaded with Paclitaxel Induce Cytotoxic Damage in Glioblastoma Brain Xenografts. Stem Cell Res. Ther. 2015, 6, 194.

(68) Pessina, A.; Leonetti, C.; Artuso, S.; Benetti, A.; Dessy, E.; Pascucci, L.; Passeri, D.; Orlandi, A.; Berenzi, A.; Bonomi, A.; et al. Drug-Releasing Mesenchymal Cells Strongly Suppress B16 Lung Metastasis in a Syngeneic Murine Model. J. Exp. Clin. Cancer Res. 2015, 34, 82 .

(69) Pessina, A.; Coccè, V.; Pascucci, L.; Bonomi, A.; Cavicchini, L.; Sisto, F.; Ferrari, M.; Ciusani, E.; Crovace, A.; Falchetti, M. L.; et al. Mesenchymal Stromal Cells Primed with Paclitaxel Attract and Kill Leukaemia Cells, Inhibit Angiogenesis and Improve Survival of Leukaemia-Bearing Mice. Br. J. Haematol. 2013, 160, 766-778.

(70) Klopp, A. H.; Spaeth, E. L.; Dembinski, J. L.; Woodward, W. a.; Munshi, A.; Meyn, R. E.; Cox, J. D.; Andreeff, M.; Marini, F. C. Tumor Irradiation Increases the Recruitment of Circulating Mesenchymal Stem Cells into the Tumor Microenvironment. Cancer Res. 2007, 67, 11687-11695.

(71) Yu, X.; Lu, C.; Liu, H.; Rao, S.; Cai, J.; Liu, S.; Kriegel, A. J.; Greene, A. S.; Liang, M.; Ding, X. Hypoxic Preconditioning with Cobalt of Bone Marrow Mesenchymal Stem Cells Improves Cell Migration and Enhances Therapy for Treatment of Ischemic Acute Kidney Injury. PLoS One 2013, 8, e62703.

(72) Das, R.; Jahr, H.; van Osch, G. J. V. M.; Farrell, E. The Role of Hypoxia in Bone Marrow-Derived Mesenchymal Stem Cells: Considerations for Regenerative Medicine Approaches. Tissue Eng. Part B. Rev. 2010, 16, 159-168.

(73) Ellem, S. J.; Taylor, R. a.; Furic, L.; Larsson, O.; Frydenberg, M.; Pook, D.; Pedersen, J.; Cawsey, B.; Trotta, A.; Need, E.; et al. A pro-Tumourigenic Loop at the Human Prostate Tumour Interface Orchestrated by Oestrogen, CXCL12 and Mast Cell Recruitment. $J$. Pathol. 2014, 234, 86-98.

(74) Mirzamohammadi, S.; Aali, E.; Najafi, R.; Kamarul, T.; Mehrabani, M.; Aminzadeh, A.; Sharifi, A. L. I. M. Effect of $17 \beta$-Estradiol on Mediators Involved in Mesenchymal Stromal Cell Trafficking in Cell Therapy of Diabetes. Cytotherapy 2015, 17, 46-57.

(75) Levy, O.; Mortensen, L. J.; Boquet, G.; Tong, Z.; Perrault, C.; Benhamou, B.; Zhang, J.; Stratton, T.; Han, E.; Safaee, H.; et al. A Small-Molecule Screen for Enhanced Homing of Systemically Infused Cells. Cell Rep. 2015, 10, 1261-1268. 
(76) Levy, O.; Zhao, W.; Mortensen, L. J.; Leblanc, S.; Tsang, K.; Fu, M.; Phillips, J. A.; Sagar, V.; Anandakumaran, P.; Ngai, J.; et al. mRNA-Engineered Mesenchymal Stem Cells for Targeted Delivery of Interleukin-10 to Sites of Inflammation. Blood 2013, 122, e23-e32.

(77) Abrami, L.; Fivaz, M.; Van Der Goot, F. G. Adventures of a Pore-Forming Toxin at the Target Cell Surface. Trends Microbiol. 2000, 8, 168-172.

(78) Degiacomi, M. T.; Iacovache, I.; Pernot, L.; Chami, M.; Kudryashev, M.; Stahlberg, H.; van der Goot, F. G.; Dal Peraro, M. Molecular Assembly of the Aerolysin Pore Reveals a Swirling Membrane-Insertion Mechanism. Nat. Chem. Biol. 2013, 9, 623-629.

(79) Williams, S. a.; Merchant, R. F.; Garrett-Mayer, E.; Isaacs, J. T.; Buckley, T. J.; Denmeade, S. R. A Prostate-Specific Antigen-Activated Channel-Forming Toxin as Therapy for Prostatic Disease. J. Natl. Cancer Inst. 2007, 99, 376-385.

(80) Abrami, L.; Fivaz, M.; Decroly, E.; Seidah, N. G.; Jean, F.; Thomas, G.; Leppla, S. H.; Buckley, J. T.; van der Goot, F. G. The Pore-Forming Toxin Proaerolysin Is Activated by Furin. J Biol Chem 1998, 273, 32656-32661.

(81) Denmeade, S. R.; Egerdie, B.; Steinhoff, G.; Merchant, R.; Abi-Habib, R.; Pommerville, P. Phase 1 and 2 Studies Demonstrate the Safety and Efficacy of Intraprostatic Injection of PRX302 for the Targeted Treatment of Lower Urinary Tract Symptoms Secondary to Benign Prostatic Hyperplasia. Eur. Urol. 2011, 59, 747-754.

(82) Elhilali, M. M.; Pommerville, P.; Yocum, R. C.; Merchant, R.; Roehrborn, C. G.; Denmeade, S. R. Prospective, Randomized, Double-Blind, Vehicle Controlled, Multicenter Phase IIb Clinical Trial of the Pore Forming Protein PRX302 for Targeted Treatment of Symptomatic Benign Prostatic Hyperplasia. J. Urol. 2013, 189, 1421-1426.

(83) Brennen, W. N.; Kisteman, L. N.; Isaacs, J. T. Rapid Selection of Mesenchymal Stem and Progenitor Cells in Primary Prostate Stromal Cultures. Prostate 2016, n/a - n/a.

(84) Janssen, S.; Rosen, D. M.; Ricklis, R. M.; Dionne, C. A.; Lilja, H.; Christensen, S. B.; Isaacs, J. T.; Denmeade, S. R. Pharmacokinetics, Biodistribution, and Antitumor Efficacy of a Human Glandular Kallikrein 2 (hK2)-Activated Thapsigargin Prodrug. Prostate 2006, $66,358-368$. 
Scheme 1 (Levy et al.)

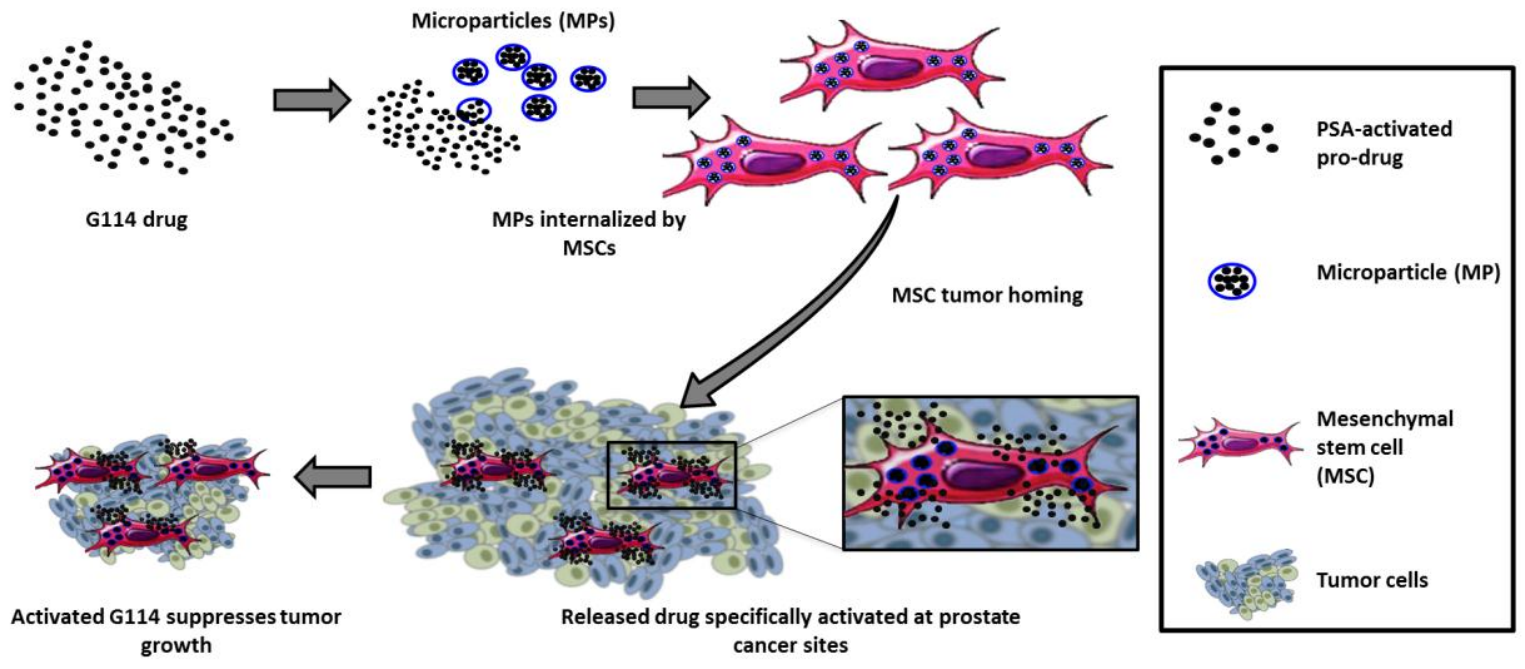


Figure-1 (Levy et al.):

a

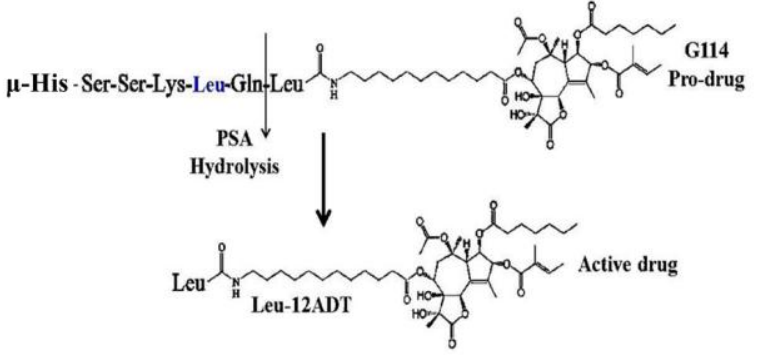

b

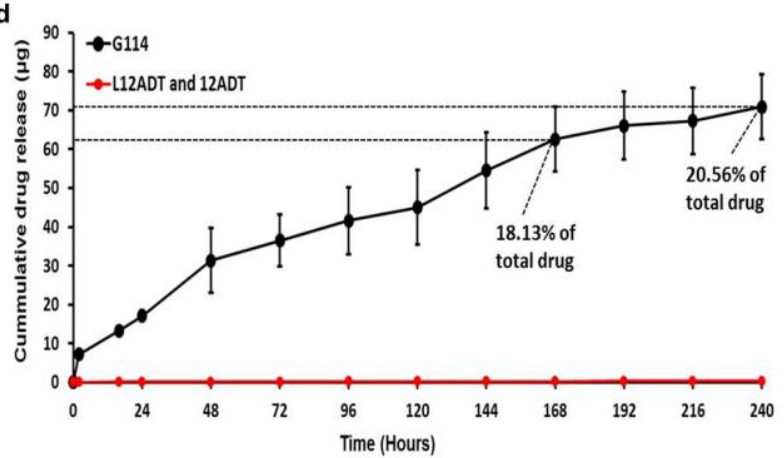

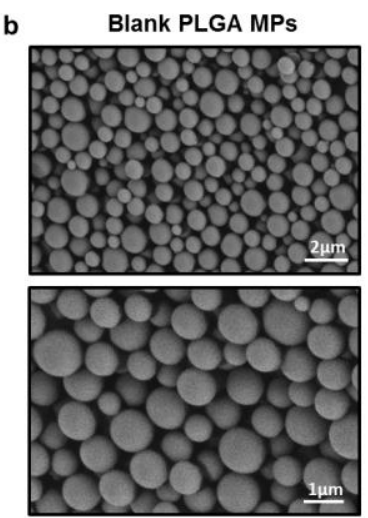

G114-loaded PLGA MPs
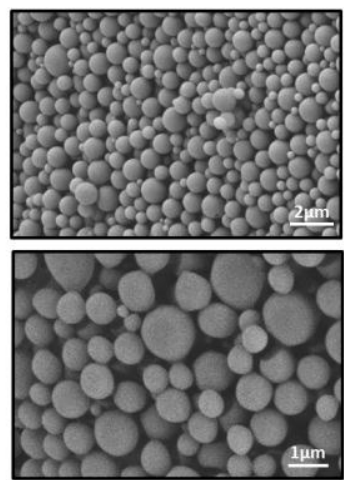

\begin{tabular}{|c|c|}
\hline Property & G114 MPs (mean \pm SD) \\
\hline Size (nm) & $948.04 \pm 73.11$ \\
\hline Polydispersity & $0.18 \pm 0.16$ \\
\hline Charge (mV) & $-8.32 \pm 3.55$ \\
\hline Drug Loading (\%) & $13.79 \pm 0.52$ \\
\hline Encapsulation Efficiency (\%) & $88.95 \pm 3.05$ \\
\hline
\end{tabular}


Figure-2 (Levy et al.):
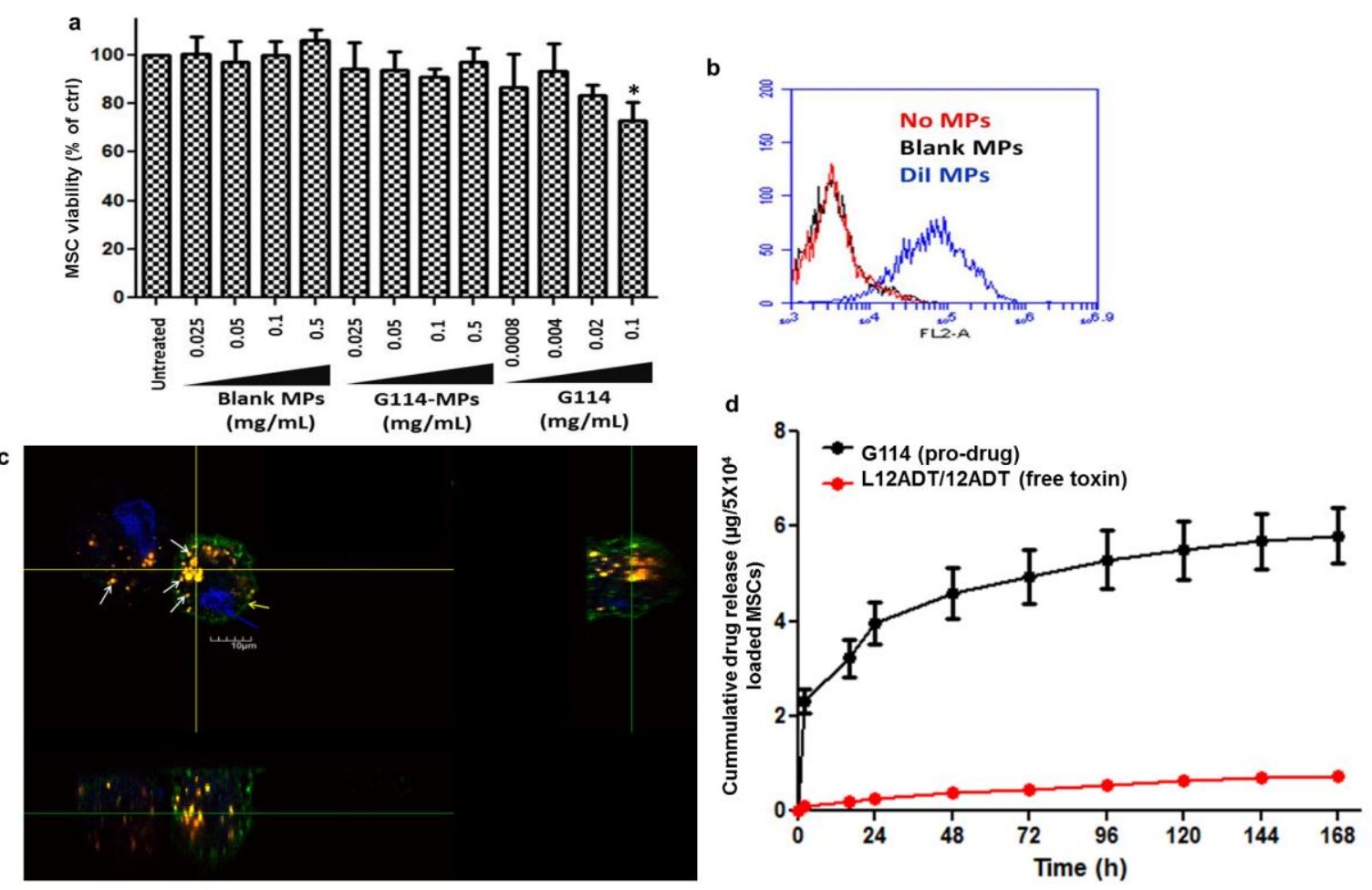
Figure-3 (Levy et al.):
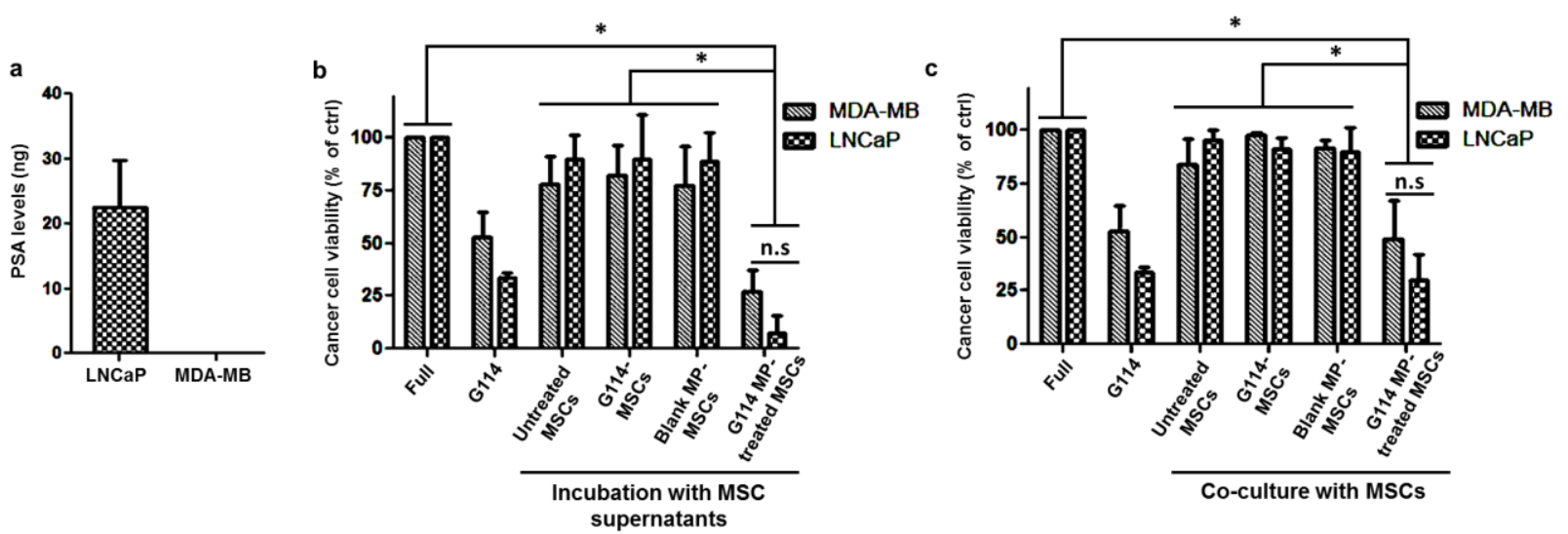


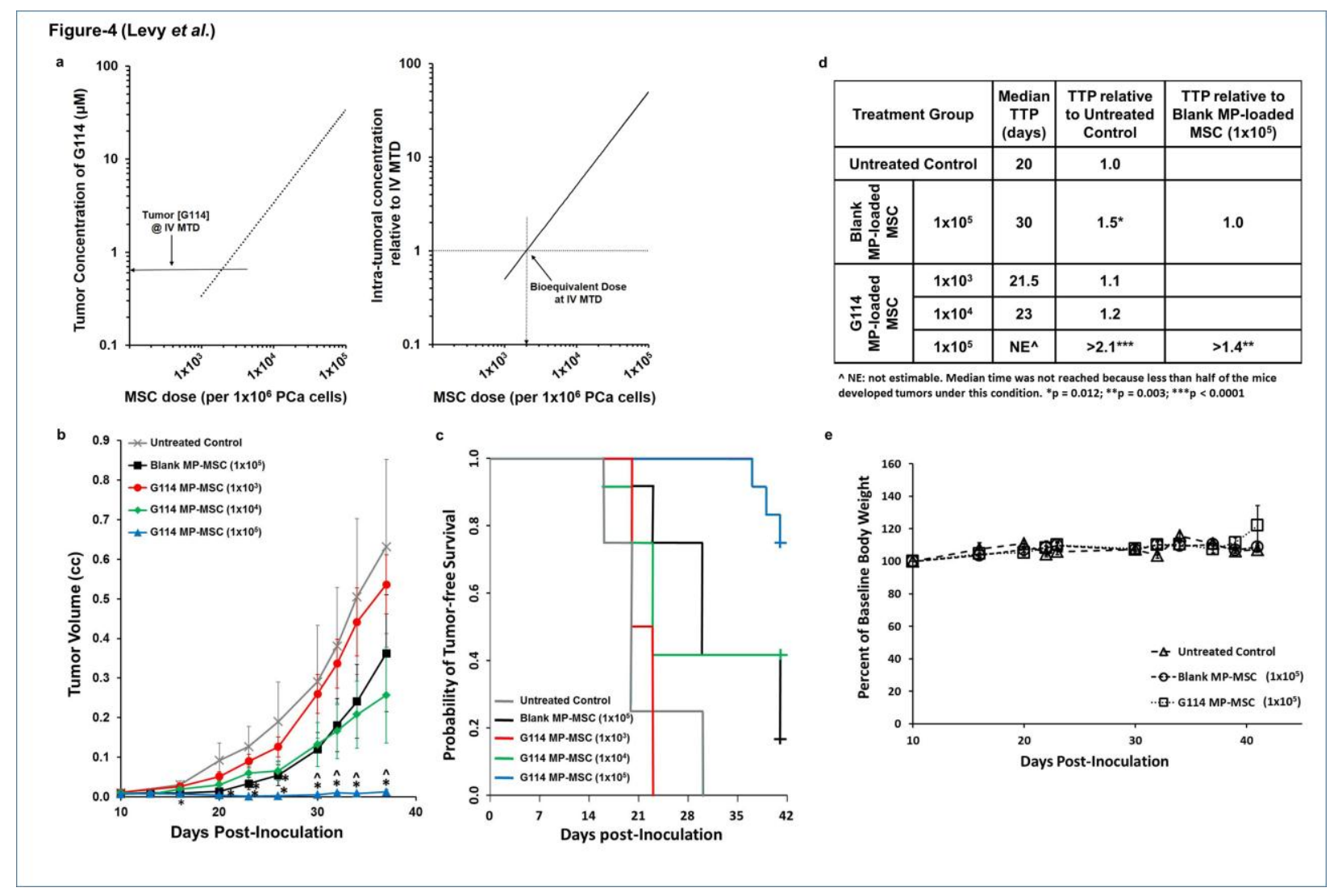

